\title{
A genome-wide BAC-end sequence survey provides first insights into sweetpotato (Ipomoea batatas (L.) Lam.) genome composition
}

Zengzhi Si, Bing Du, Jinxi Huo, Shaozhen He, Qingchang Liu* and Hong Zhai

\begin{abstract}
Background: Sweetpotato, Ipomoea batatas (L.) Lam., is an important food crop widely grown in the world. However, little is known about the genome of this species because it is a highly heterozygous hexaploid. Gaining a more in-depth knowledge of sweetpotato genome is therefore necessary and imperative. In this study, the first bacterial artificial chromosome (BAC) library of sweetpotato was constructed. Clones from the BAC library were end-sequenced and analyzed to provide genome-wide information about this species.
\end{abstract}

Results: The BAC library contained 240,384 clones with an average insert size of $101 \mathrm{~kb}$ and had a 7.93-10.82 × coverage of the genome, and the probability of isolating any single-copy DNA sequence from the library was more than $99 \%$. Both ends of 8310 BAC clones randomly selected from the library were sequenced to generate 11,542 high-quality BAC-end sequences (BESs), with an accumulative length of 7,595,261 bp and an average length of $658 \mathrm{bp}$. Analysis of the BESs revealed that $12.17 \%$ of the sweetpotato genome were known repetitive DNA, including $7.37 \%$ long terminal repeat (LTR) retrotransposons, $1.15 \%$ Non-LTR retrotransposons and $1.42 \%$ Class II DNA transposons etc., $18.31 \%$ of the genome were identified as sweetpotato-unique repetitive DNA and $10.00 \%$ of the genome were predicted to be coding regions. In total, 3,846 simple sequences repeats (SSRs) were identified, with a density of one SSR per $1.93 \mathrm{~kb}$, from which 288 SSRs primers were designed and tested for length polymorphism using 20 sweetpotato accessions, 173 (60.07\%) of them produced polymorphic bands. Sweetpotato BESs had significant hits to the genome sequences of $I$. trifida and more matches to the whole-genome sequences of Solanum lycopersicum than those of Vitis vinifera, Theobroma cacao and Arabidopsis thaliana.

Conclusions: The first BAC library for sweetpotato has been successfully constructed. The high quality BESs provide first insights into sweetpotato genome composition, and have significant hits to the genome sequences of I. trifida and more matches to the whole-genome sequences of Solanum lycopersicum. These resources as a robust platform will be used in high-resolution mapping, gene cloning, assembly of genome sequences, comparative genomics and evolution for sweetpotato.

Keywords: Sweetpotato, BAC library, BAC-end sequence, SSRs, Comparative genome

\footnotetext{
*Correspondence: liuqc@cau.edu.cn; zhaihong@cau.edu.cn

Beijing Key Laboratory of Crop Genetic Improvement/Laboratory of Crop Heterosis and Utilization, Ministry of Education, China Agricultural University, Beijing 100193, China
} International License (http://creativecommons.org/licenses/by/4.0/), which permits unrestricted use, distribution, and reproduction in any medium, provided you give appropriate credit to the original author(s) and the source, provide a link to the Creative Commons license, and indicate if changes were made. The Creative Commons Public Domain Dedication waiver (http://creativecommons.org/publicdomain/zero/1.0/) applies to the data made available in this article, unless otherwise stated. 


\section{Background}

Sweetpotato, Ipomoea batatas (L.) Lam., is an important food crop widely grown in the world. More than 104 million tons are produced globally, 95\% of which are grown in developing countries [1]. It is also an alternative source of bioenergy as a raw material for fuel production [2]. The orange-fleshed sweetpotato is rich in beta-carotene, which plays a crucial role in preventing vitamin A deficiency-related blindness and maternal mortality [3]. In addition, polyphenols in sweetpotato leaves are found to suppress the growth of human cancer cells [4]. Sweetpotato is a highly heterozygous and self-incompatible autohexaploid $(2 n=6 x=90)$ and little is known about its genome [5].

Recently, de novo whole-genome sequencing of the selfed line $\mathrm{Mx} 23 \mathrm{Hm}$ and the highly heterozygous line 0431-1 of I. trifida $(2 \mathrm{n}=2 \times=30$, the likely diploid ancestor of sweetpotato) was performed using the Illumina HiSeq platform, but their assembly and annotation are still in the early stages [6]. Transcriptome sequencing of sweetpotato provided an important transcriptional data source for studying storage root formation, flower development and carotenoid and anthocyanin biosynthesis of this species [7-13]. Lang et al. [14] reported the complete nucleotide sequence of the chloroplast genome of sweetpotato using the next-generation sequencing technology. However, the full genomic sequence of the cultivated sweetpotato is still absent.

Bacterial artificial chromosome (BAC) libraries are valuable resources for genome sequencing, physical mapping, analysis of gene structure and function and comparative genomics, in particular for the species unsequenced or of complex genome structure [15-18]. Sequencing the ends of BAC clones is an efficient strategy to produce low-pass genomic sequences, which are used to estimate genome properties such as genome organization and composition, to identify macro- and micro-synteny between species, to facilitate the assembly of contigs into scaffolds during whole genome sequencing and to develop molecular markers [19-22]. BAC-end sequences (BESs) analyses have been conducted in number of plant species such as rice [15], maize [23], wheat [24], apple [25], Spartina maritima [26], sugarcane [27], coffee [28] and passion fruit [29]. To date, the BAC library of sweetpotato has not been constructed.

In the present study, the first BAC library of sweetpotato was constructed. Clones from the BAC library were end-sequenced and analyzed to provide genomewide information about sweetpotato. The analyses focused on GC content, repeat element composition, protein encoding regions, simple sequence repeat (SSR) and genome comparison between sweetpotato and other plants.

\section{Results}

BAC library construction and characterization

A sweetpotato BAC library was constructed using sweetpotato line $\mathrm{Xu} 781$ with high dry-matter content and stem nematode resistance by partial digestion of its nuclear DNA with HindIII. The BAC library consisted of 240,384 BAC clones stored in 626 (384wells) microtitre plates, from which 240 clones were randomly selected to estimate the average insert size. The insert size ranged from 15 to $305 \mathrm{~kb}$, with an average size of $101 \mathrm{~kb}$. The majority $(75.42 \%)$ of the clones had insert sizes of $>90 \mathrm{~kb}, 15.83 \%$ between 40 $\mathrm{kb}$ and $90 \mathrm{~kb}, 1.67 \%<40 \mathrm{~kb}$ and $7.08 \%$ no insert (Fig. 1). Based on the sweetpotato genome size of 2200-3000 Mb [5], the BAC library had a 7.93-10.82 $\times$ coverage of the genome, and the probability of isolating any single-copy DNA sequence from the library was more than $99 \%$.

A subset of the library consisting of 1,152 individual BAC clones was screened using mitochondrial and chloroplast gene specific primers. The results indicated that the library had a very low frequency of clones derived from the mitochondrial genome $(0.26 \%)$ and chloroplast genome (0.43\%).

To check the utility of the library in gene isolation, the library was screened with special primers complementary to the sequences of two sweetpotato genes, IbPPOS (GenBank: AY822711.1) and IbMIPS1 [30]. It was found that 14 and 33 clones harbored IbPPOS and IbMIPS1, respectively, showing the availability of the BAC library for gene isolation.

\section{BAC-end sequences}

A total of 8,310 clones were sequenced from both forward and reverse directions and 16,620 raw data reads were produced (Table 1). After trimming BESs for vector and low read quality sequences, 11,598 BESs with a quality score of $\geq 20$ and a sequence length $\geq 100$ bp were obtained. An additional set of 56 BESs was filtered out due to high similarity to Arabidopsis mitochondria (GenBank: NC_001284.2) or chloroplast (GenBank: NC_000932.1). The remaining 11,542 BESs, including 9,894 paired-end reads and 1,648 unpaired reads, represented about $7.6 \mathrm{Mb}(\sim 0.30 \%)$ of the sweetpotato genome and their lengths ranged from $100 \mathrm{bp}$ to $945 \mathrm{bp}$, with an average length of $658 \mathrm{bp}$. In terms of length distribution, 700-799 bp were the most abundant categories, accounting for $35.18 \%(4,061)$ of all BESs, followed by $600-699$ bp $(20.82 \%, 2,403)$ and $800-899$ bp (17.91\%, 2,067) (Fig. 2). The GC content was $38.18 \%$, indicating that the sweetpotato genome is AT-rich (Table 1). All BESs of length $\geq 100$ bp were deposited to the GenBank GSS database (accession numbers KS309164-KS320705). 

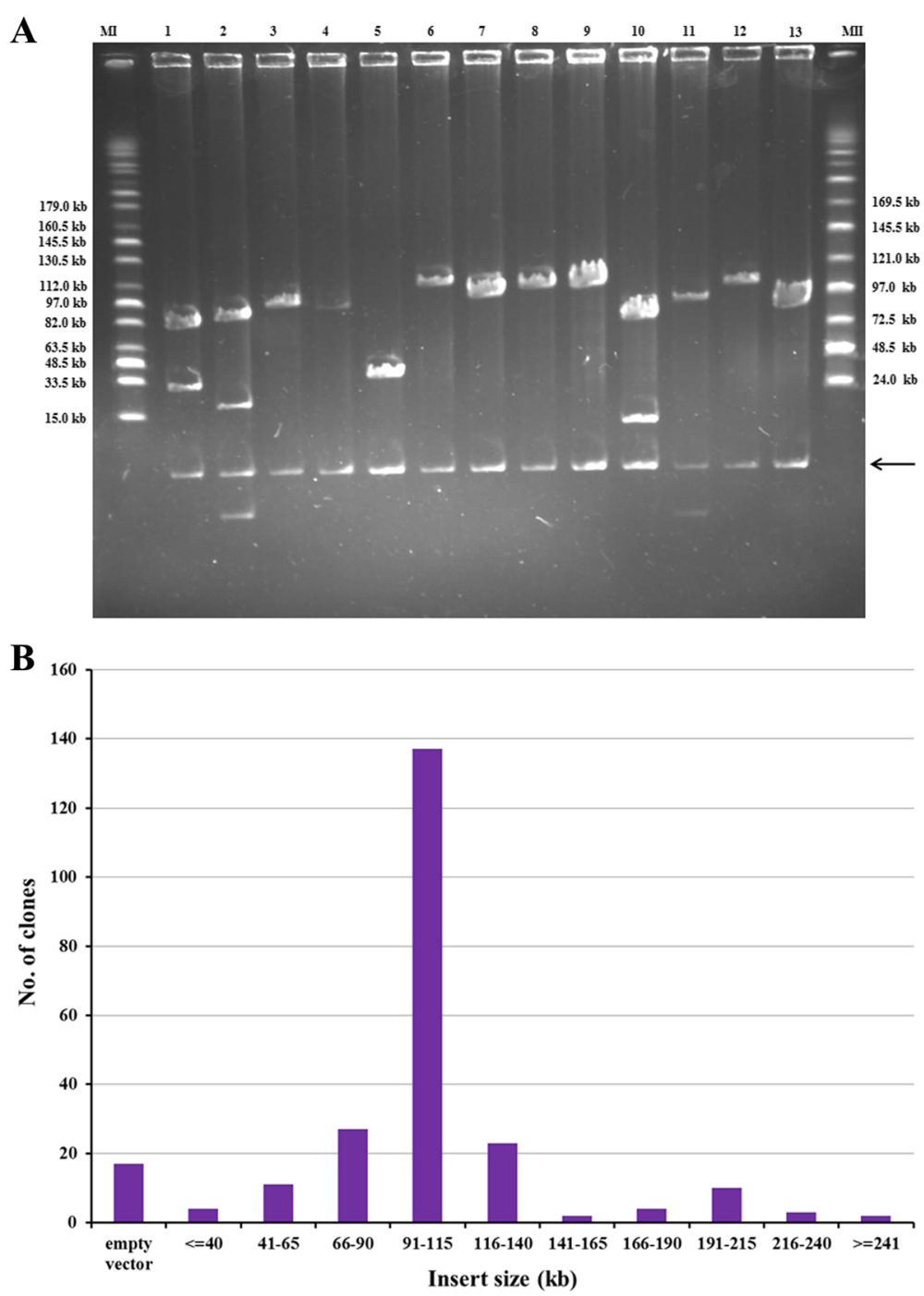

Fig. 1 Insert size analysis of the sweetpotato BAC library. a Pulsed filed gel electrophoresis of 13 BAC clones DNA digested with Not I (Lanes 1-13). MI was MidRange I PFG Marker; MII was MidRange II PFG Marker. The arrow shows the $8.1 \mathrm{~kb}$ band of the cloning vector. $\mathbf{b}$ Distribution of the insert size of 240 randomly selected sweetpotato BAC clones

Table 1 Summary of BAC-end sequencing

\begin{tabular}{ll}
\hline Total number of BESs & 16,620 \\
\hline No. of BESs with organellar DNA & 56 \\
$\begin{array}{l}\text { No. of good quality BESs (Phred quality } \\
\text { score >20, read length > 100 bp) }\end{array}$ & 11,542 \\
No. of paired BESs & 9,894 \\
No. of non-paired BESs & 1,648 \\
Total length of BESs (bp) & $7,595,261$ \\
Minimum length of BESs (bp) & 100 \\
Maximum length of BESs (bp) & 945 \\
Average length of BESs (bp) & 658.10 \\
GC content (\%) & 38.18 \\
No. of BESs with repetitive DNA & 7,114 \\
No. of BESs with protein coding region & 2,088 \\
\hline
\end{tabular}

\section{Repetitive DNA content and composition}

Based on similarity searches in the repeat database, $12.17 \%(924,646 \mathrm{bp})$ of the nucleotides in the sweetpotato BESs were identified as known repetitive DNA elements (Table 2). Class I retrotransposons were the most abundant repeats, representing $69.92 \%$ of the total repetitive DNA content and $8.51 \%$ of the total genomic sequence. They were subdivided into LTR retrotransposons and Non-LTR retrotransposons. LTR retrotransposons, included Ty1-Copia elements and Ty3-Gypsy elements, accounted for $86.52 \%$ of the total retrotransposons and $7.37 \%$ of the genomic sequence. The number of Ty3-gypsy $(1,008)$ was slightly higher than that of Ty1-copia (873). Non-LTR retrotransposons, including short interspersed elements (SINEs) and long interspersed elements (LINEs), represented 13.48\% of 


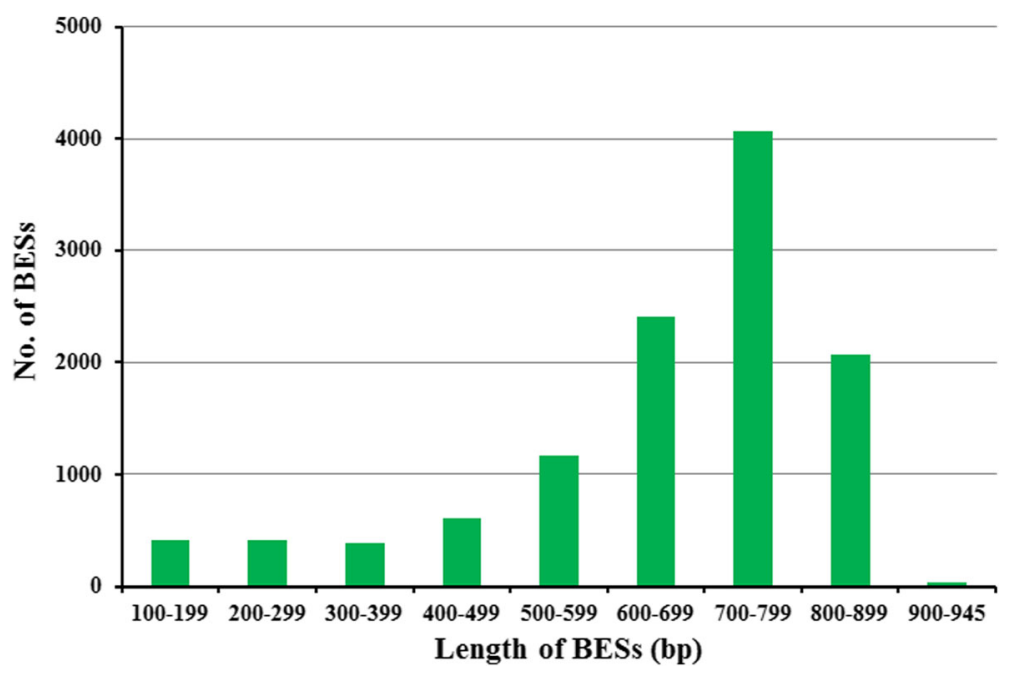

Fig. 2 Sizes distribution of the sweetpotato BESs

Table 2 Classification and distribution of repetitive DNA elements in BESs

\begin{tabular}{lllc}
\hline Class & Number & $\begin{array}{l}\text { Length } \\
\text { occupied (bp) }\end{array}$ & $\begin{array}{c}\text { Percentage of } \\
\text { the genome }\end{array}$ \\
\hline Class I retrotransposon & 2,414 & 646,519 & 8.51 \\
LTR retrotransposons & 1,984 & 559,396 & 7.37 \\
Ty1/copia & 873 & 276,307 & 3.64 \\
Gypsy/DIRS & 1,008 & 274,869 & 3.62 \\
Others & 103 & 8,220 & 0.11 \\
Non-LTR & 430 & 87,123 & 1.15 \\
retrotransposons & & & \\
SINE & 15 & 1,018 & 0.01 \\
LINE & 415 & 86,105 & 1.13 \\
Class II DNA & 673 & 107,599 & 1.42 \\
transposons & & & 0.35 \\
hobo-Activator & 168 & 26,272 & 0.03 \\
TCMar & 26 & 2,226 & 0.26 \\
CMC-EnSpm & 133 & 19,577 & 0.27 \\
MULE-MuDR & 116 & 20,521 & 0.38 \\
RC/Helitron & 102 & 29,024 & 0.00 \\
PiggyBac & 1 & 85 & 0.03 \\
Tourist/Harbinger & 24 & 2,340 & 0.10 \\
Others & 103 & 7,554 & 0.01 \\
Unclassfied & 11 & 752 & 12.17 \\
Total interspersed & 3,098 & 754,870 & \\
repeats & & & 0.04 \\
Small RNA & 34 & 4,925 & \\
Satellites & 26 & 2,954 & 147,234 \\
Simple repeats & 3,408 & 26,125 & \\
Low complexity & 550 & 924,646 & \\
Total repetitive DNA & 7,116 & \\
\hline
\end{tabular}

the total retrotransposons and $1.15 \%$ of the genomic sequence. The number of LINEs (415) exceeded that of SINEs (15). A total of 673 Class II DNA transposons were predicted, representing $11.63 \%$ of the total repetitive DNA content and $1.42 \%$ of the total genomic sequence. The hobo-Activator was found to be the most elements (168), followed by CMC-EnSpm (133), MULEMuDR (116) and RC/Helitro (102). In addition, simple repeats, low complexity, small RNA and satellite elements were also identified (Table 2).

A total of 242 repeat families were detected by RepeatModeler and the lengths ranged from 51 to $889 \mathrm{bp}$. Ten of them were eliminated due to containing hits to transposon related proteins. The remaining 232 families were not found in the public repeat database and considered as sweetpotato novel repetitive elements, 49 of which were classified as DNA transposons, 92 as LTRs, 28 as LINEs, 10 as SINEs and 53 as unknown. These sweetpotato unique repeats were used as a custom library for RepeatMasker and masked a total of 1,390,919 bp, equivalent to $18.31 \%$ of the total genomic sequence. Together with the known repeats, the total repetitive DNA content in sweetpotato genome was about $30.48 \%$.

\section{Protein coding regions and functional annotation}

After masking the known and novel repeats, the remaining 4,428 BESs were used to identify protein coding regions. A total of 3,360 BESs were found to be homologous to the sweetpotato express sequence tags (ESTs) downloaded from NCBI GenBank and derived from our in-house transcriptome data (unpublished), accounting for $16.43 \%(1,248,033 \mathrm{bp})$ of the total length of sweetpotato BESs (Additional file 1: Table S1); 1,526 BESs were of significant hits to NCBI-ESTs database, accounting for $4.77 \%$ (362,031 bp) of sweetpotato BESs 
(Additional file 2: Table S2). Taken together, 3,422 BESs were homologous to ESTs databases, with a cumulative match length of $1,270,851 \mathrm{bp}$, representing $16.73 \%$ of the total BESs dataset (Additional file 3: Table S3). Of these, 2,088 BESs were also of significant hits to NCBI NR database and the cumulative match length was $760,248 \mathrm{bp}$, accounting for $10.00 \%$ of the total BESs dataset (Additional file 4: Table S4). The majority of the top-hits were to Solanum lycopersicum (414 BESs),
Nicotiana sylvestris (185 BESs), N. tomentosiformis (158 BESs), Vitis vinifera (157 BESs), S. tuberosum (125 BESs), Coffea canephora (105 BESs) and Theobroma cacao (88 BESs) (Fig. 3).

Functional annotation showed that 6,790 ontological terms were assigned to $1,526 \mathrm{BESs}$. These BESs were further classified into three categories: cellular components (866), molecular functions $(1,185)$ and biological processes (919) (Fig. 4). Of the BESs in the cellular

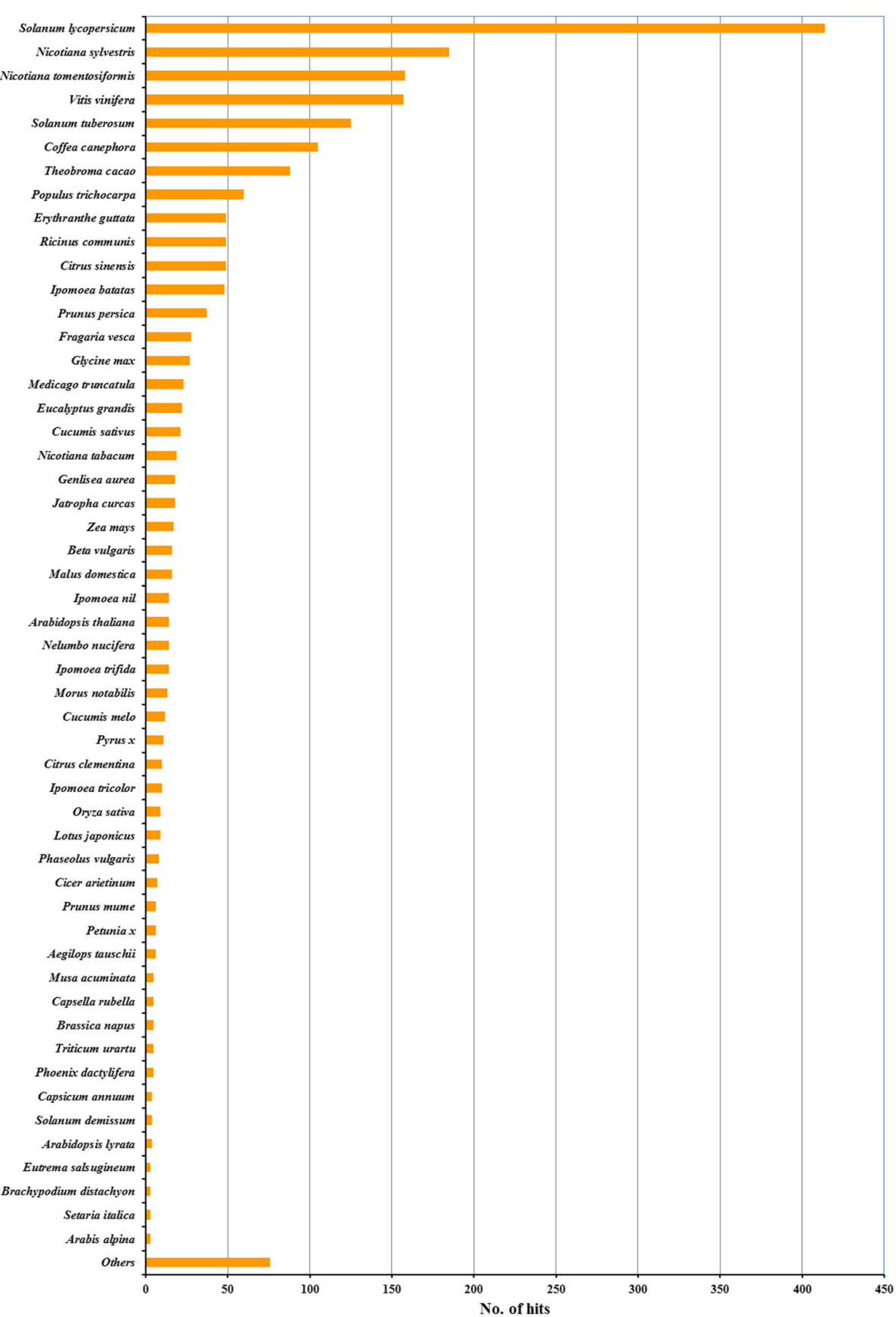

Fig. 3 List of plant species that had significant hits to the sweetpotato BESS 
A
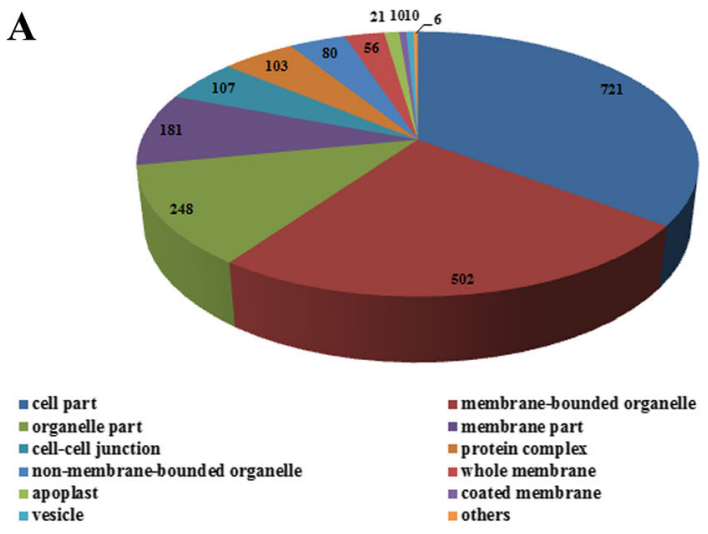

B

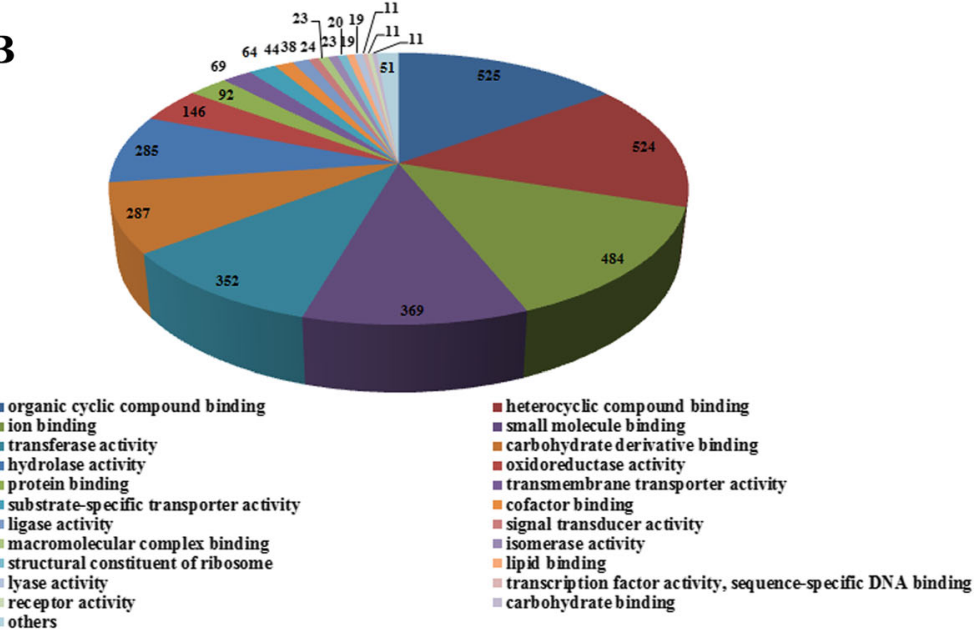

C

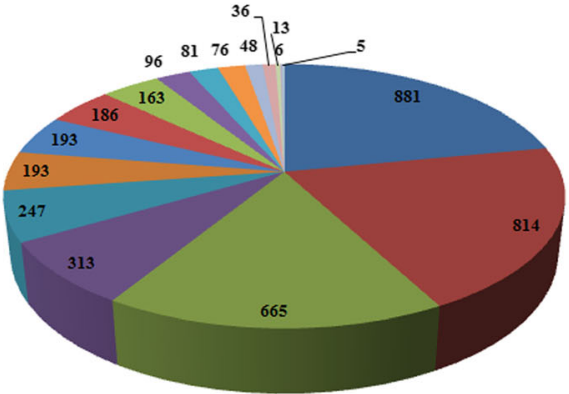

- metabolic process

single-organism proces

m biologic al regulation

cellular comp onent organization or biogenesis

In signaling

= immune system process

rhythmic process

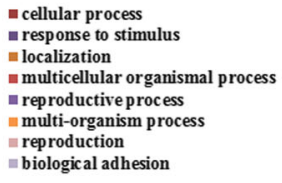

biological adhesio

Fig. $4 \mathrm{GO}$ classification of the predicted protein-coding genes from the sweetpotato BESs. a Cellular components. b Molecular functions. c Biological processes

components category, $721(83.26 \%)$ were for cell part, $502(57.97 \%)$ for membrane-bounded organelle and 248 (83.26\%) for organelle part. The BESs in molecular functions category were distributed as follows: organic cyclic compound binding $(525,44.30 \%)$, heterocyclic compound binding $(524,44.22 \%)$, ion binding $(484,40.84 \%)$, small molecule binding $(369,31.14 \%)$, transferase activity (352, 29.70\%), carbohydrate derivative binding (287, $24.22 \%)$ and hydrolase activity $(285,24.05 \%)$. The most represented biological processes were metabolic process (881, 95.87\%), hydrolase activity $(814,88.57 \%)$ and single-organism process $(665,72.36 \%)$. 
A total of 2,210 BESs had significant matches to the protein database of $S$. lycopersicum, with a cumulative match length of $773,346 \mathrm{bp}$, representing $10.18 \%$ of the total BESs dataset (Additional file 5: Table S5). Based on an estimated sweetpotato genome size of 2200-3000 $\mathrm{Mb}$, the total coding region length of the sweetpotato genome was predicted to 217.78-296.97 Mb. If the average coding region length in sweetpotato was $1,379 \mathrm{bp}$, as in S. lycopersicum, the total gene content of the sweetpotato genome might be $157,926-215,351$. As compared to the $V$. vinifera protein database, 2,127 BESs showed significant matches, accounting for $9.87 \%$ (749,931 bp) of the total BESs dataset (Additional file 6: Table S6). The total coding region length of sweetpotato was estimated as 217.14-296.10 $\mathrm{Mb}$ and the number of genes was predicted as 146,792-199,932, assuming that an average coding region length was $1,481 \mathrm{bp}$ as in $V$. vinifera. A total of 2,764 and 2,638 BESs showed significant hits to the CDS databases of Mx23Hm and 0431-1 of $I$. trifida $(2 \times)$, representing $10.71 \%(813,709 \mathrm{bp})$ and $11.23 \%(852,756 \mathrm{bp})$ of the total BESs dataset, respectively (Additional file 7: Table S7 and Additional file 8: Table S8). The coding regions in sweetpotato were estimated as 235.70-321.40 $\mathrm{Mb}$ and 247.00-336.82 $\mathrm{Mb}$ and the number of genes was predicted as 153,446-209,245 and 200,816-273,840, according to a gene CDS length of $1,536 \mathrm{bp}$ in $\mathrm{Mx} 23 \mathrm{Hm}$ and 1,230 bp in 0431-1, respectively.

\section{Simple sequence repeats (SSRs)}

The 11,542 BESs were subjected to a search for SSRs and a total of 3,846 SSRs were identified from 2,698 BESs. The average density of SSRs in sweetpotato BESs was one SSR per $1.93 \mathrm{~kb}$. Most of SSRs were mono-
(54.71\%), di- (31.44\%) and trinucleotide repeats (12.04\%), with less abundant tetra- (1.35\%), penta- $(0.31 \%)$ and hexanucleotide repeats $(0.16 \%)$ (Additional file 9: Table S9). A/T motifs were the most common mononucleotide repeats, while $\mathrm{G} / \mathrm{C}$ motifs were present at a much lower frequency (Fig. 5). The most frequently occurring motifs were AT/AT in the dinucleotide repeats and AAT/ATT in the trinucleotides repeats. Thus, AT-rich SSRs were consistently more abundant than GC-rich SSRs. Of the 3,846 SSRs, 3,161 were perfect SSRs containing a single repeat motif, and 685 were compound SSRs composed of two or more SSRs separated by $\leq 100 \mathrm{bp}$. The perfect SSRs were further subdivided into Class I ( $\geq 20 \mathrm{bp}$ in length, 34.55\%) and Class II (10-19 bp in length, 65.45\%) according to the method of Temnykh et al. [31]. Di- (53.70\%) and trinucleotide motifs $(20.79 \%)$ were of most abundance in class I SSRs, while mononucleotide motifs (66.46\%) were most frequently occurred in class II SSRs.

The distribution and frequency of different types of SSRs in sweetpotato BESs were compared with those in the ESTs (Fig. 5). A total of 45,649 EST-SSRs were identified from the sweetpotato ESTs $(166,866,793 \mathrm{bp})$ downloaded from NCBI GenBank and derived from our in-house transcriptome data (unpublished) using MicroSAtellite (MISA). The mononucleotide repeats were the most abundant type $(59.35 \%)$, followed by di- (21.76\%), tri- $(17.19 \%)$, tetra- $(1.40 \%)$, penta- $(0.23 \%)$ and hexanucleotide repeats $(0.08 \%)$, showing a consistent trend with those in BES-SSRs. Compared to BES-SSRs, the most common motifs were also $\mathrm{A} / \mathrm{T}$ in mononucleotide ESTSSRs, but the most frequently occurring motifs were $\mathrm{AG} / \mathrm{CT}$ in the dinucleotide repeats and AAG/CTT in the trinucleotides repeats (Fig. 5). Furthermore, the average density of SSRs in the ESTs was one SSR per

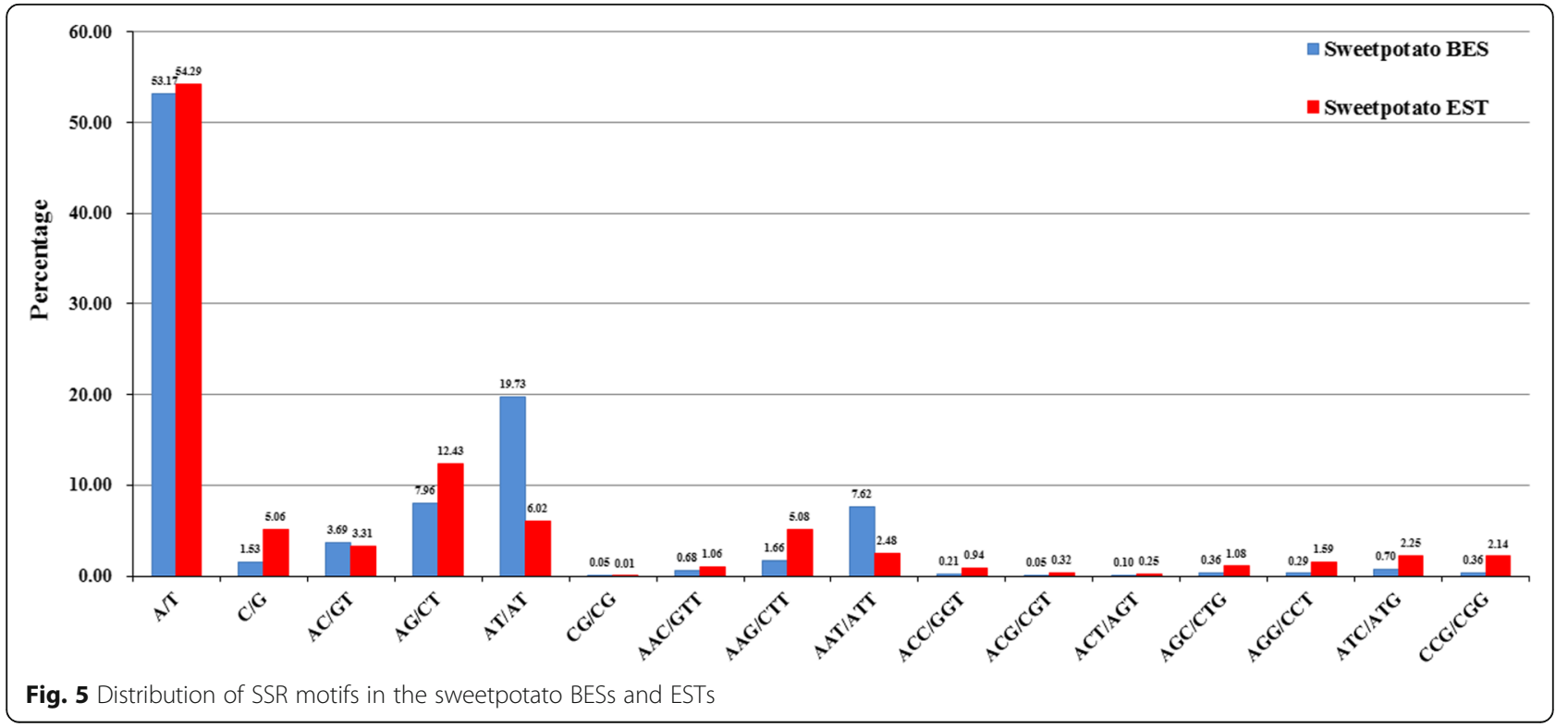


$3.66 \mathrm{~kb}$, which was approximately a half of BESs (one SSR per $1.93 \mathrm{~kb}$ ), indicating that potential SSRs are more numerous in BESs than in ESTs.

For comparison purposes, analyses were performed to identify BES-SSRs of other species. A consistent trend was found that the proportion of the corresponding SSRs decreased as the length of motif unit increased in most of the surveyed species. Mono-, di- and trinucleotide repeats were dominant in all of the surveyed species, accounting for more than $97 \%$ of the total SSRs (Additional file 9: Table S9). The AT-rich SSRs frequently occurred in all of the surveyed species (Fig. 6). In addition, sweetpotato showed a higher density of SSRs among the surveyed species (Additional file 9: Table S9).

Of the 3,846 SSRs, 288 were chosen to design primers for assessing their allelic polymorphisms with 20 sweetpotato accessions (Additional file 10: Table S10.). The 248 primer pairs $(86.11 \%)$ successfully amplified products from at least 1 of the 20 tested accessions and 173 primer pairs $(60.07 \%)$ produced polymorphic bands among the 20 tested accessions on denaturing polyacrylamide gels (Additional file 11: Figure S1A). Furthermore, the 173 polymorphic primer pairs were assessed for their allelic polymorphisms with the 20 sweetpotato accessions and 109 of them (37.85\%) produced polymorphic bands on agarose gels (Additional file 11: Figure S1B). Twelve of the 109 primer pairs were chosen to amplify $168 F_{1}$ individuals derived from a cross between Xushu 18 and $\mathrm{Xu} 781$ and 11 of them generated polymorphic bands on agarose gels (Additional file 12: Figure S2).

\section{Comparative genome analysis}

The 11,542 sweetpotato BESs were compared to the genome sequences of $\mathrm{Mx} 23 \mathrm{Hm}$ and $0431-1$ of I. trifida (2x). A total of 11,229 (97.29\%) and 11,320 (98.08\%)
BESs had significant hits to the genome sequences of $\mathrm{Mx} 23 \mathrm{Hm}$ and $0431-1$, respectively. The matches were scattered in 4,658 contigs of $\mathrm{Mx} 23 \mathrm{Hm}$ and 6,738 contigs of 0431-1, with a cumulative match length of 6,229,456 bp (82.02\% of the total BESs length) and $6,154,441 \mathrm{bp}$ (81.03\%), respectively. Of these BESs, 689 and 210 paired $\mathrm{BESs}$ were aligned on the same contigs of $\mathrm{Mx} 23 \mathrm{Hm}$ and 0431-1, respectively, in the correct orientation within 15-350 kb apart (Additional file 13: Table S11 and Additional file 14: Table S12). These results support that sweetpotato has a highly close relationship with I. trifida $(2 \times)$.

These BESs were also compared to the sequenced $S$. lycopersicum, $V$. vinifera, $T$. cacao and $A$. thaliana genomes to identify microsyntenic regions. $N$. sylvestris, N. tomentosiformis, S. tuberosum and C. canephora genomes are still in the early stages of their assembly and annotation and are not suitable for comparative mapping studies [29] though they had the high number of top hits to sweetpotato.

According to the method of Rampant et al. [32], the matches are classified into 2 categories: 'single end' (SE) and 'paired end' (PE). The PE category is subdivided into 'non-colocalized' and 'colocalized' and the latter includes 'collinear,' 'rearranged' and 'gapped'. A total of 491 BESs (477 SEs and 14 PEs) were matched to the genome sequences of S. lycopersicum (Fig. 7). Twelve of the 14 PEs were 'non-colocalized', and 2 (R358H9 and F358H9) mapped to the S. lycopersicum chromosome 3 within $\sim 69 \mathrm{~kb}$ apart fell into the 'collinear' category, suggesting the presence of one putative microsyntenic region between sweetpotato and S. lycopersicum (Fig. 7). R358H9 began at position $65,487,266 \mathrm{bp}$ and F358H9 terminated at position 65,556,186 bp (Fig. 8). This region contained 15 genes, seven on sense strand and eight on antisense

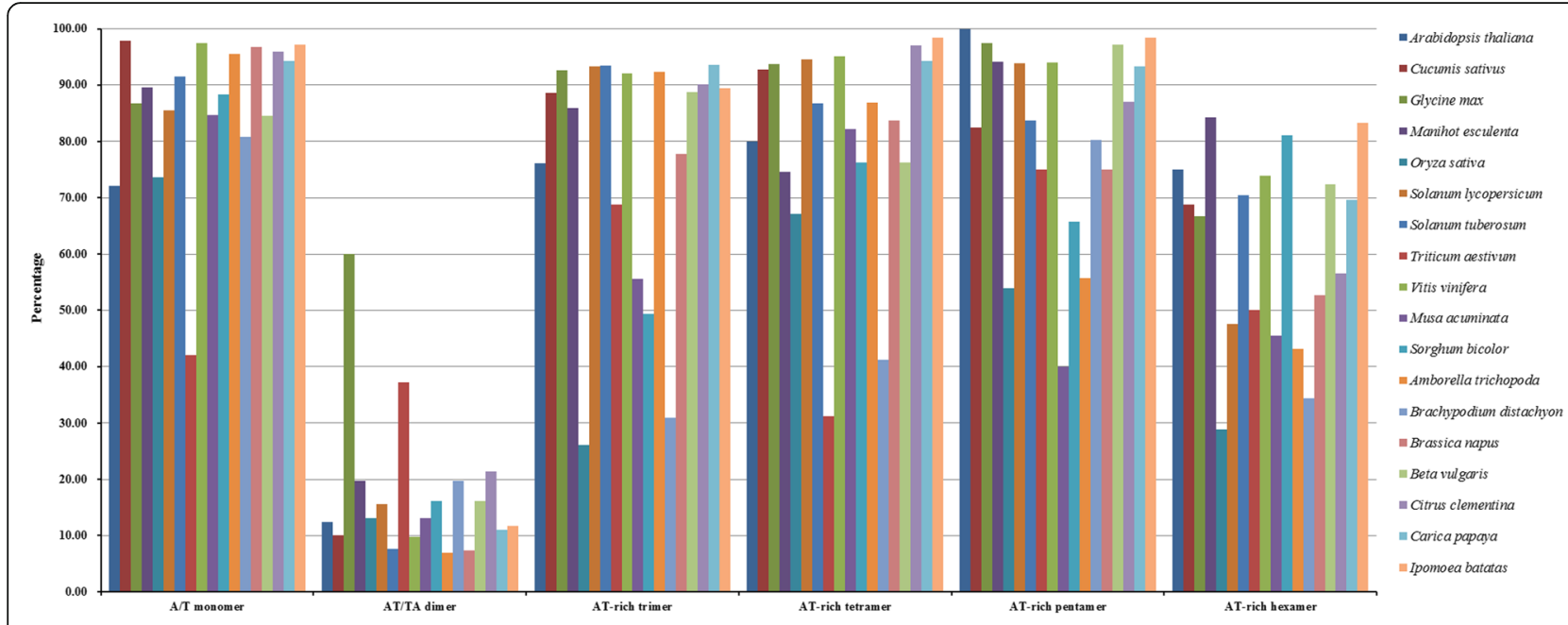

Fig. 6 Frequency of AT-rich repeat motifs in BESs of sweetpotato and other plant species 


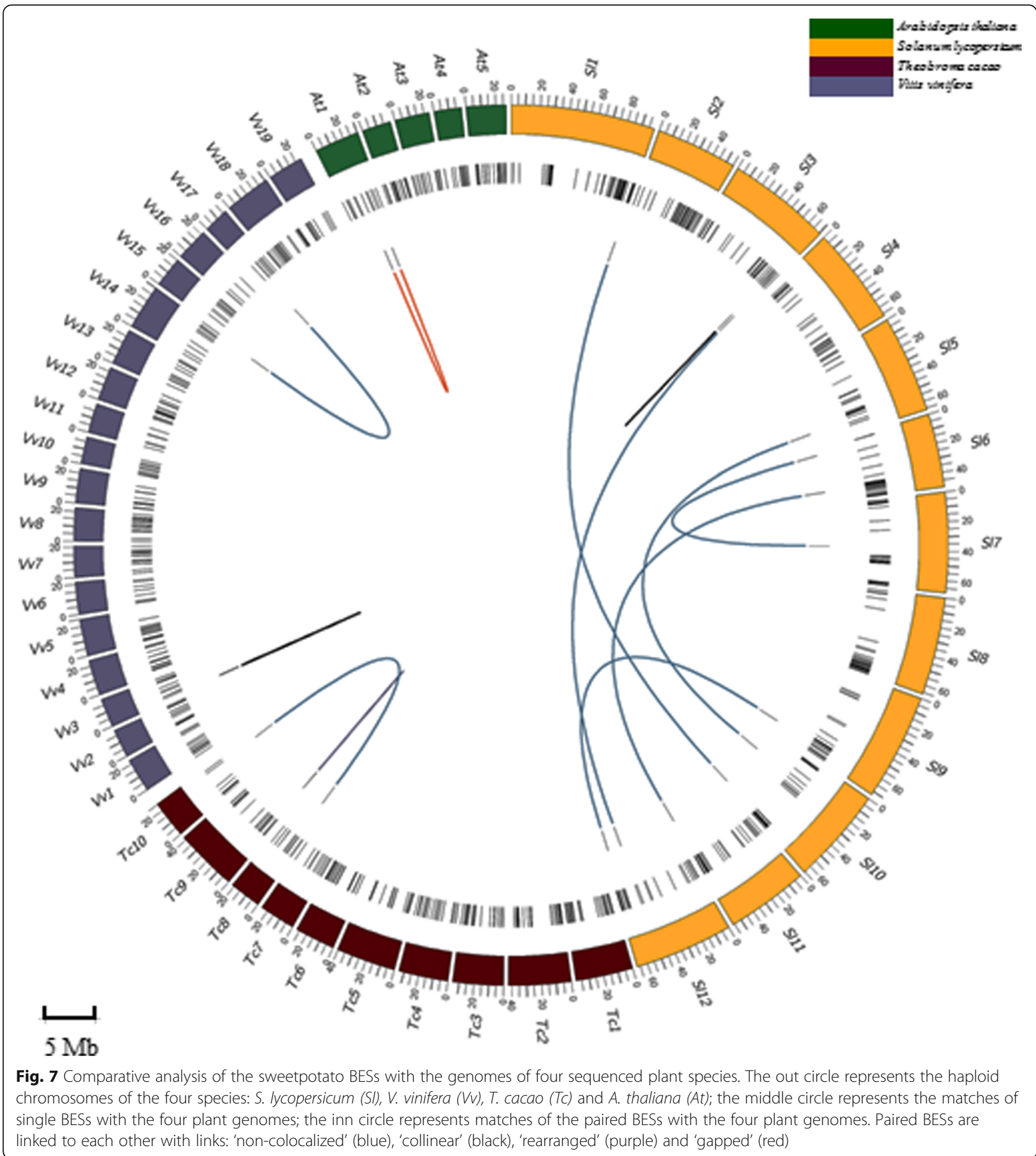

strand (Fig. 8). Comparative mapping between sweetpotato and $V$. vinifera revealed 272 matches, including 268 SEs, 2 'non-colocalized' and 2 'collinear' (R157E19 and F157E19). R157E19 and F157E19 formed 'collinear' alignment on the $V$. vinifera chromosome 3 within $\sim 310 \mathrm{~kb}$ apart, the reverse end beginning at position $1,882,624 \mathrm{bp}$ and the forward end terminating at position 2,193,110 bp. This region encompassed 32 genes, 9 on sense strand and
23 on antisense strand (Fig. 8). In addition, 221 matches (217 SEs, 2 'non-colocalized' and 2 'rearranged') to the $T$. cacao genome and 99 matches (97 SEs and 2 'gapped') to the $A$. thaliana genome were identified (Fig. 7). In the perspective of the whole genome, the matches dispersed on all chromosomes of $S$. lycopersicum, $V$. vinifera, $T$. cacao and A. thaliana and 36 of them were found in all of the four genomes (Fig. 7, Additional file 15: Table S13). 

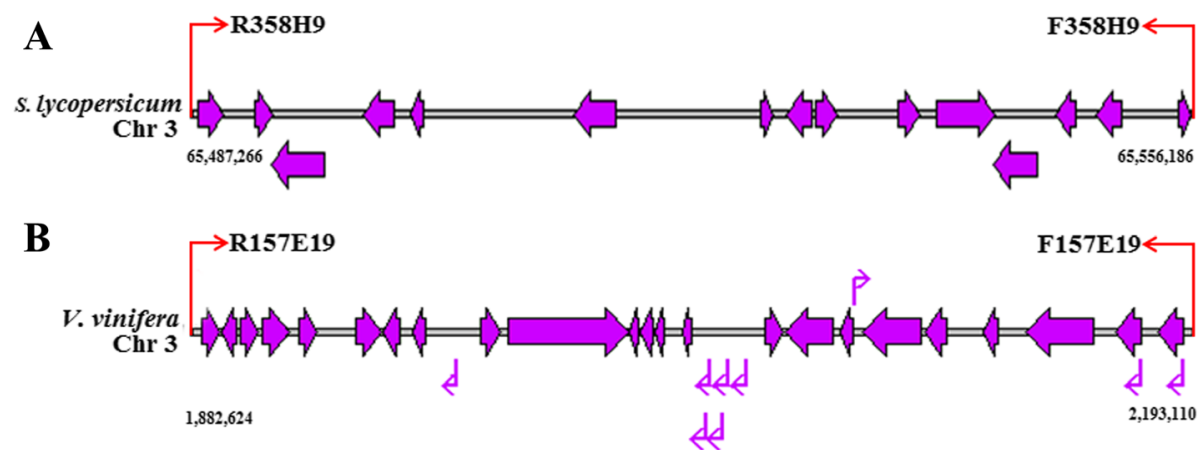

Fig. 8 Analysis of microsyntenic regions between sweetpotato BACs and S. lycopersicum (a) and V. vinifera (b) genomes. The red arrows represent the positions that paired ends of a sweetpotato BAC matched on the chromosomes of S. Iycopersicum (a) and V. vinifera (b); the purple arrows represent the genes distributed on the chromosomes of S. lycopersicum (a) and $V$. vinifera (b); the arrows (red and purple) in right direction represent matching on sense strand, the arrows (red and purple) in left direction represent matching on antisense strand

\section{Discussion}

Sweetpotato is a highly heterozygous autohexaploid and its genomic BAC library has not been reported to date. In the present study, the BAC library of sweetpotato was successfully constructed using the elite line $\mathrm{Xu} 781$ of this crop. The BAC library consisted of 240,384 clones, the majority $(75.42 \%)$ of which had insert sizes of $>90$ $\mathrm{kb}$, with an average insert size of $101 \mathrm{~kb}$, similar to the results reports in several plant species such as sugar beet [33], peanut [34], narrow-leafed lupin [35] and passion fruit [29]. Thus, this library has a reasonably large average insert size. The BAC library provided a 7.93$10.82 \times$ coverage of the sweetpotato genome, with more than $99 \%$ probability of isolating any single-copy DNA sequence from the library. The coverage of this library is greater than those of peanut [34] and passion fruit [29], and comparable to those of sugar beet [33] and narrow-leafed lupin [35]. Additionally, the present library was constructed from a partial digestion of genomic DNA using only one restriction enzyme (HindIII), which was also used to construct the libraries of sugar beet (BamHI) [33], peanut (HindIII) [34], narrow-leafed lupin (BamHI) [35] and passion fruit (HindIII) [29]. This might lead to preferential cloning owing to the uneven distribution of restriction sites throughout the genome, which could be minimized by developing more clones for the library using one or two new restriction enzymes in the future $[33,36]$. This is the first large-insert BAC library for sweetpotato and a valuable tool for future sequencing and genome studies.

The present study provides a first overview of the structure and composition of the sweetpotato genome through the analysis of 11,542 high quality BESs. The GC content of the sweetpotato genome was $38.18 \%$, comparable to the $38.45 \%$ of the chloroplast genome of this species and the $35.6-36.0 \%$ of I. trifida $(2 \times)[6,14]$.
Therefore, these results suggest that the genomes of sweetpotato and its wild relatives are all AT-rich.

Repetitive DNA, as a significant portion of most eukaryotic genomes, plays important roles during polyploidization and post-polyploidization changes [37, 38]. The I. trifida $(2 \times)$ genome is estimated to be composed of $42.3-47.7 \%$ repeats [6]. Repetitive sequences account for at least $62.2 \%$ of the assembled potato genome [39] and this proportion reaches approximately $80 \%$ in wheat [40]. The present results revealed that the repetitive DNA in the sweetpotato genome was approximately $30.48 \%$, with $12.17 \%$ homologous to known repeats and $18.31 \%$ specific to sweetpotato. The proportion of repeats in sweetpotato might be underestimated, as reported in many plant species such as $S$. tuberosum, $S$. lycopersicum and $S$. maritime $[26,36]$.

It is known that transposable elements have important consequences on genome structure and functions [41]. The present study indicated that Class I retrotransposons $(8.51 \%)$ were significantly predominant compared to Class II DNA transposons (1.42\%) in the sweetpotato genome, as in other plant genomes [39, 40, 42]. Further analysis revealed that the percentage of Class I retrotransposons was much larger in sweetpotato than in I. trifida (4.8-5.2\%), but the proportion of Class II DNA transposons in sweetpotato was comparable to that in I. trifida (1.4-1.5\%). Ty1-copia and Ty3-gypsy retrotransposons are two main types of LTRs, playing important roles in maintaining chromatin structures and centromere functions and regulating gene expression in the host genomes [43]. The ratio of Ty3-Gypsy:Ty1-Copia in sweetpotato was approximately 1.15:1, indicating that the contributions of Ty3-gypsy and Ty1-copia to the sweetpotato genome were approximately equal. This ratio is similar to those of Passiflora edulis (1:1) [29], $M$. guttatus (1:1), Prunus persica (1:1.18) and P. edulis (1.06:1), but lower than those of S. lycopersicum (2.45:1), 
S. tuberosum (2.48:1), $V$. vinifera (1:3) and $A$. thaliana (2.94:1) [28]. In addition, the novel repetitive elements were found in the sweetpotato genome. They were classified as DNA transposons, LTRs, LINEs, SINEs and unknown. These repeats should be further used to study genome structure and functions of sweetpotato.

The proportion of the sweetpotato BESs with potential coding regions was moderate compared to the assessment of coding regions in many BES-based studies [26, 27, 44-46]. The cumulative coding region length was $760,248 \mathrm{bp}$, representing $10.00 \%$ of the total sweetpotato BESs length. Based on matches to the protein databases of $S$. lycopersicum and $V$. vinifera, the total coding sequences of the sweetpotato genome were predicted to be $217.40-296.97 \mathrm{Mb}$ and the gene content was estimated as 146,792-215,351. Thus, the gene content is much higher in sweetpotato than in diploid I. trifida $(62,407-109,449)$ [6]. The large gene content might be caused by highly heterozygosity and the polyploidy nature of sweetpotato [5].

SSR markers are widely used for genome analysis and map comparison and consensus due to their abundance, functionality, high polymorphism and excellent reproducibility [47]. BESs have been proven to be valuable sources of SSRs $[48,49]$. In our study, a total of 3,846 SSRs were identified from the 2,698 sweetpotato BESs. The average density of SSRs was one SSR per $1.93 \mathrm{~kb}$ in sweetpotato, close to those in Carica papaya (one SSR per $1.72 \mathrm{~kb}$ ), A. thaliana (one SSR per $1.82 \mathrm{~kb}$ ), Amborella trichopoda (one SSR per $1.88 \mathrm{~kb}$ ) and Citrus clementine (one SSR per $1.99 \mathrm{~kb}$ ), and higher than those in the other surveyed species (Additional file 9: Table S9). Our results also showed that potential SSRs were more numerous in the sweetpotato BESs than in the ESTs, as reported in walnut and coffee $[19,28]$. Furthermore, the amplification results indicated that the $60.07 \%$ of primer pairs designed from the chosen SSRs exhibited good polymorphism among 20 sweetpotato accessions with differences in yield, quality and diseases resistance (Additional file 11: Figure S1), which was higher than $32.26 \%$ of primer pairs from EST-SSRs reported by Wang et al. [50]. The present BES-SSRs also showed good polymorphism among $168 \mathrm{~F}_{1}$ individuals of Xushu $18 \times \mathrm{Xu} 781$ (Additional file 12: Figure S2). Therefore, these BES-SSRs can be used to identify germplasm, assess genetic diversity, construct genetic linkage maps and develop molecular markers for agronomically important traits in sweetpotato.

Cytogenetic and molecular genetic evidences indicate that I. trifida $(2 \times)$ is the most likely diploid ancestor of the hexaploid sweetpotato [51-54]. In the present study, $97.29 \%$ and $98.08 \%$ of the sweetpotato BESs were matched to the genome sequences of $\mathrm{Mx} 23 \mathrm{Hm}$ and 0431-1 of I. trifida $(2 \times)$, covering $82.02 \%$ and $81.03 \%$ of the total BESs length, respectively. These results provide the genomic evidence for the highly close relationship between sweetpotato and I. trifida $(2 \times)$. Moreover, the BAC clones, with both ends aligned on the same contigs of I. trifida $(2 \times)$ in the correct orientation within 15-350 $\mathrm{kb}$ apart, were also identified and might be used in comparative genomics study between sweetpotato and I. trifida. Comparative mapping between both species can not be performed due to the fact that I. trifida genome is still in the early stages of its assembly and annotation [6].

Well-sequenced species with the highest number of top hits are commonly used as reference genomes for the BAC-end analysis of target species [26-29, 32]. Our study revealed that more sweetpotato BESs were matched to $S$. lycopersicum than $V$. vinifera, $T$. cacao and A. thaliana (Fig. 7). It is consistent with the fact that sweetpotato and S. lycopersicum, belonging to Solanales, diverged from a common ancestor approximately $82-86$ million years ago, while the divergence between sweetpotato and $V$. vinifera, $T$. cacao and A. thaliana is estimated to be approximately 123-125 million years ago [55]. More sweetpotato BESs were matched to the genome of $V$. vinifera than those of $T$. cacao and $A$. thaliana, which might be because $V$. vinifera did not undergo recent genome duplication [56]. Similarly, the limited number of sweetpotato BESs matched to the $A$. thaliana genome might be because the $A$. thaliana genome suffered many gene losses since its two wholegenome duplications [56]. These findings provide an interesting starting point for comparative genomics and evolution studies of sweetpotato.

\section{Conclusions}

The first genomic BAC library for sweetpotato has been successfully constructed. It has a highly redundant genome coverage $(7.93-10.82 \times)$, and contains large inserts $(101 \mathrm{~kb})$ and a very low frequency of clones derived from the mitochondrial genome and chloroplast genome. The high quality BESs provide first insights into sweetpotato genome composition, including GC content, transposable elements and protein coding regions, and have significant hits to the genome sequences of I. trifida and more matches to the whole-genome sequences of Solanum lycopersicum. SSRs identified from the BESs show good polymorphism in sweetpotato. These resources as a robust platform will be used in high-resolution mapping, gene cloning, assembly of genome sequences, comparative genomics and evolution for sweetpotato.

\section{Methods}

Plant materials

The sweetpotato line $\mathrm{Xu} 781$ was used to construct a BAC Library. Xu 781 was selected from bulked seeds of 
JPKY0-015 in an open-pollinated poly-cross and conserved at our laboratory [57]. It has high dry-matter content and stem nematode resistance and is extensively used as a parent in sweetpotato breeding programs in China. After plants were grown in the dark for 7 days, their young leaves were collected and rapidly frozen by submersion in liquid nitrogen, followed by temporarily storing at $-80{ }^{\circ} \mathrm{C}$ for DNA isolation.

\section{BAC library construction}

About 20 g leaves of $\mathrm{Xu} 781$ were ground into powder in a mortar containing liquid nitrogen. The isolation of high molecular weight (HMW) DNA was conducted according the procedure of Zhang et al. [58]. Four DNA plugs were partially digested for $8 \mathrm{~min}$ at $37^{\circ} \mathrm{C}$ with 0 , 10, 20, and 30 units of HindIII (New England Biolabs, Beijing, China), respectively, to determine optimal partial digestion conditions. The digested plugs were separated by two rounds of pulsed field gel electrophoresis (PFGE) at $6 \mathrm{~V} / \mathrm{cm}$ with a $5-15 \mathrm{~s}$ switch time for $16 \mathrm{~h}$ at $14{ }^{\circ} \mathrm{C}$ to elute DNA fragments ranging from $100 \mathrm{~kb}$ to $300 \mathrm{~kb}$ in size. The target DNA fragments were ligated into the CopyControl $^{\mathrm{m}} \mathrm{pCC}^{\mathrm{B}} \mathrm{BAC} \mathrm{C}^{\mathrm{m} \mathrm{m}}$ Vector (Epicentre Biotechnologies, Madison, WI, United States) at $16{ }^{\circ} \mathrm{C}$ overnight. Two $\mu \mathrm{l}$ of the ligation product were used to transform $20 \mu \mathrm{l}$ of E. coli EPI300 cells (Epicentre Biotechnologies, Madison, WI, United States) by electroporation at $14 \mathrm{KV} / \mathrm{cm}$. The cells were then cultured on Luria Broth (LB) medium containing $12.5 \mu \mathrm{g} / \mathrm{ml}$ chloramphenicol, $60 \mu \mathrm{g} / \mathrm{ml}$ 5-bromo-4chloro-3-indolyl- $\beta$-d-galactopyranoside $(\mathrm{X}$-Gal) and 15 $\mu \mathrm{g} / \mathrm{ml}$ isopropyl $\beta$-D-1-thiogalactopyranoside (IPTG) for $24 \mathrm{~h}$ at $37^{\circ} \mathrm{C}$. Recombinant clones were picked manually, arrayed into 384-well plates containing $80 \mu \mathrm{l}$ of LB freezing medium with $12.5 \mu \mathrm{g} / \mathrm{ml}$ chloramphenicol, incubated at $37^{\circ} \mathrm{C}$ overnight, and then stored at $-80^{\circ} \mathrm{C}$.

\section{BAC library characterization}

A set of clones randomly selected from the BAC library were cultured in $4 \mathrm{ml}$ LB medium containing $12.5 \mu \mathrm{g} / \mathrm{ml}$ chloramphenicol on a reciprocal shaker (200 strokes/min) at $37{ }^{\circ} \mathrm{C}$ overnight. Plasmid DNA $(\sim 1 \mu \mathrm{g})$ of the BAC clones was isolated according to standstard alkaline-lysis method [59], and digested with $5 \mathrm{U}$ of restriction enzyme NotI (New England Biolabs, Beijing, China). The digested products were separated by PFGE on an $1 \%$ agarose gel at $6 \mathrm{~V} / \mathrm{cm}$ with a $5-15 \mathrm{~s}$ switch time for $16 \mathrm{~h}$ at $14{ }^{\circ} \mathrm{C}$, and the electrophoresis results were detected by ethidium bromide (EB) staining. The insert size of each clone was determined by comparing the bands to MidRange PFG Marker I and MidRange PFG Marker II (New England Biolabs, Beijing, China). The genome coverage of the BAC library and the probability of isolating any single-copy DNA sequence from the library were estimated according to the method of Clarke and Carbon [60].
A set of the BAC clones were randomly selected as templates for PCR to estimate the level of contamination by organellar DNA. Primers for 2 mitochondrial genes (matR, GenBank: GU351235.1; nad5, GenBank: GU351439.1) and 2 chloroplast genes (psaA, GenBank: KP212149.1; psbA, GenBank: KP212149.1) (Additional file 16: Table S14) were designed by Primer3 [61, 62]. The reaction mixture consisted of $2 \mu \mathrm{l} 10 \times$ PCR buffer, $1.6 \mu \mathrm{l} 2.5 \mathrm{mM}$ dNTPs, $1 \mu \mathrm{l}$ of each primer $(10 \mu \mathrm{M}), 1 \mu \mathrm{l}(\sim 50 \mathrm{ng})$ BAC DNA, $0.2 \mu \mathrm{l}(1$ U) EasyTaq DNA Polymerase (TransGen Biotech, Beijing, China) and 14.2 $\mu$ l double-distilled water. PCR amplifications were programmed as follows: $94{ }^{\circ} \mathrm{C}$ for $5 \mathrm{~min}$, followed by 35 cycles of $94{ }^{\circ} \mathrm{C}$ for $30 \mathrm{~s}, 60^{\circ} \mathrm{C}$ for $30 \mathrm{~s}, 72{ }^{\circ} \mathrm{C}$ for $30 \mathrm{~s}$, and then a final $10 \mathrm{~min}$ extension at $72{ }^{\circ} \mathrm{C}$. PCR products were gently mixed with $4 \mu \mathrm{l} 6 \times$ DNA loading buffer (TransGen Biotech, Beijing, China), and then $5 \mu \mathrm{l}$ of the mixture were loaded onto a $1 \%$ agarose gel and separated by electrophoresis at $6 \mathrm{~V} / \mathrm{cm}$ for $21 \mathrm{~min}$ at room temperature. Electrophoresis results were detected by GoldView (YeaSen, Beijing, China) staining.

To identify the BAC clones containing sweetpotato genes of interest, the library was screened using the primers designed from cDNA sequences of sweetpotato myo-inositol-1-phosphate synthase gene (IbMIPS1) and polyphenol oxidase gene (IbPPOS) (Additional file 16: Table S14) as described by Farrar et al. [63]. The BAC clones with target sequence were identified by PCR amplifications as described above.

\section{BAC-end sequencing}

A set of the BAC clones were randomly selected and incubated in 96-well deep-well plates containing $1.5 \mathrm{ml}$ of $2 \times$ LB medium with $12.5 \mu \mathrm{g} / \mathrm{ml}$ chloramphenicol for $20 \mathrm{~h}$ on a reciprocal shaker (200 strokes/min) at $37{ }^{\circ} \mathrm{C}$. BAC DNA was isolated and purified using standstard alkaline-lysis method [59]. BAC-end sequencing was performed in the forward and reverse directions using BigDye Terminator $\mathrm{V}$ 1.1 and ABI PRISM 3730 DNA Analyzer technologies (Applied Biosystems, Life Technologies Corporation, Foster, CA, United States) at Corporation of Beijing Genomics Institute (BGI), China. Base calling of ABI trace files was conducted using Phred software [64]. The bases with Phred quality score $<20$ were trimmed, and the vector sequences were subsequently removed using CROSS_MATCH [65]. After filtering out the sequences with a length shorter than $100 \mathrm{bp}$, the organellar DNA sequences were removed by comparing the BESs with the Arabidopsis mitochondrial genome (GenBank: NC_001284.2) or chloroplast genome (GenBank: NC_000932.1) using BLASTN with an E-value cutoff of 1e-15.

\section{Repetitive sequence identification}

The repetitive sequences in the sweetpotato BESs were identified and masked by searches for similarity to 
sequences in the eukaryote section of the RepBase repeat database (ver. 2013042) with CROSS_MATCH and RepeatMasker [66]. The masked sequences were further scanned to identify de novo repeats using RepeatModeler [67]. The repeats were compared against the NCBI NR database using BLASTX with an E-value cutoff of $1 \mathrm{e}-06$, and then the repeats containing hits to transposon related proteins were eliminated from the list of novel repeats. The novel repeats were classified using TEclass [68], and then were used as a custom library for RepeatMasker to further mask repetitive sequences in the sweetpotato BESs.

\section{Function annotation}

The sweetpotato BESs without known and novel repeats were analyzed for protein coding regions by comparing with the sweetpotato ESTs downloaded from NCBI GenBank and derived from our in-house transcriptome data (unpublished), NCBI-EST database and I. trifida (Mx23Hm and 0431-1) CDS databases [6] using BLASTN with an E-value cutoff of 1e-10. Further analysis for these BESs was conducted by comparing with NCBI NR protein database, S. lycopersicum protein database [69] and $V$. vinifera protein database [70] using BLASTX with an E-value cutoff of 1e-06. The total match lengths of these searches were calculated to estimate the protein coding regions and gene content in sweetpotato. BLAST2GO software was used for GO functional annotation and classification [71].

\section{SSR detection}

BES-SSRs types (mononucleotide to hexanucleotide) were identified using MISA [72]. The distribution and frequency of SSRs in the sweetpotato BESs were compared with those in sweetpotato ESTs downloaded from NCBI GenBank and derived from our in-house transcriptome data (unpublished) and in other species BESs downloaded from NCBI [73]. All of the analyses required a minimum length of $20 \mathrm{bp}$ for mononucleotide repeats and at least $15 \mathrm{bp}$ for dinucleotide-to-hexanucleotide repeats, and two or more SSRs separated by $\leq 100 \mathrm{bp}$ were considered as a compound SSR.

Twenty sweetpotato accessions, Zhenghong 22, Yushu 10, Jishu 10, Jishu 98, Xu 43-14, Lushu 3, Shangshu 19, Lizixiang, Xu 781, Xushu 18, Dayebai, Norin 1, Tielizi, Shagenshao, Beijing 553, Nancy Hall, Datouhuang, Jinguahuang, Baidumian and Mengziyanghong (Additional file 17: Table S15) and $168 \mathrm{~F}_{1}$ individuals of Xu 781 and Xushu 18 were used to assess polymorphisms of the developed SSRs. PCR amplifications were performed according to the method of Zhao et al. [57]. PCR products were separated by electrophoresis on the $5 \%(\mathrm{w} / \mathrm{v})$ denaturing polyacrylamide gels and $3 \%(\mathrm{w} / \mathrm{v})$ agarose gels, respectively.

\section{Comparative genome analysis}

The sweetpotato BESs were compared with the genome sequences of $\mathrm{Mx} 23 \mathrm{Hm}$ and $0431-1$ of I. trifida [6] using BLASTN with an E-value cutoff of 1e-06. The BLASTN results were further filtered based on criteria: identity $\geq 70 \%$, alignment length $\geq 50$ bp [26]. Furthermore, these BESs were compared with the sequenced S. lycopersicum, $V$. vinifera, T. cacao and $A$. thaliana genomes downloaded from NCBI [73] to identify the potential microsynteny using BLASTN with an E-value cutoff of 1e-06. The BLASTN results were further filtered as mentioned above. The matches were classified according to the method of Rampant et al. [32]. The best matches between sweetpotato BESs and S. lycopersicum, $V$. vinifera, $T$. cacao and $A$. thaliana genomes were used for synteny visualization using the Circos program [74].

\section{Additional files}

Additional file 1: Table S1. The BLASTN searching results of 4428 BESs with sweetpotato EST database. (XLS 635 kb)

Additional file 2: Table S2. The BLASTN searching results of 4428 BESs with NCBI EST database. (XLS 288 kb)

Additional file 3: Table S3. The BLASTN searching results of 4428 BESs with sweetpotato EST and NCBI EST database. (XLS $646 \mathrm{~kb}$ )

Additional file 4: Table S4. The BLASTX searching results of 3422 BESs with NCBI NR database. (XLS 397 kb)

Additional file 5: Table S5. The BLASTX searching results of 4428 BESS with protein databases of S. lycopersicum. (XLS 416 kb)

Additional file 6: Table S6. The BLASTX searching results of 4428 BESS with protein databases of $V$. vinifera. (XLS $400 \mathrm{~kb}$ )

Additional file 7: Table S7. The BLASTN searching results of 11542 BESs with $\mathrm{M} \times 23 \mathrm{Hm}$ database. (XLS $479 \mathrm{~kb}$ )

Additional file 8: Table S8. The BLASTN searching results of 11542 BESs with 0431-1 database. (XLS $466 \mathrm{~kb}$ )

Additional file 9: Table S9. Distribution and frequency of SSRs detected in different plant species. (XLS 28 kb)

Additional file 10: Table S10. List of 288 SSR pairs developed from the sweetpotato BESs for assessing their polymorphisms. (XLS 75 kb)

Additional file 11: Figure S1. PCR amplification of the 20 sweetpotato accessions using the 6 BESs-SSR pairs. (A) Denaturing polyacrylamide gels. M1: GeneRuler ${ }^{\mathrm{TM}}$ 50bp DNA Ladder; M2: GeneRuler ${ }^{\mathrm{TM}}$ 100bp DNA Ladder. (B) Agarose gels. M: BL 2000 DNA Marker. (JPG 632 kb)

Additional file 12: Figure S2. PCR amplification of Xu 781 (I) and Xushu 18 (II) and their $168 \mathrm{~F}_{1}$ individuals with BES_SSR_267. M: BL 2000 DNA Marker; Lanes 1 to 168: 168 individuals. (TIF 1647 kb)

Additional file 13: Table S11. Paired BESs aligned on the same contigs of $\mathrm{M} \times 23 \mathrm{Hm}$ in the correct orientation. (XLS $106 \mathrm{~kb}$ )

Additional file 14: Table S12. Paired BESs aligned on the same contigs of 0431-1 in the correct orientation. (XLS $50 \mathrm{~kb}$ )

Additional file 15: Table S13. The 36 BESs matched to all the four sequenced genomes. (XLS $30 \mathrm{~kb}$ )

Additional file 16: Table S14. Primers used for screening BAC library. (XLS 26 kb)

Additional file 17: Table S15. Sweetpotato accessions used for BES-SSRs validation and evaluation. (XLSX $11 \mathrm{~kb}$ )

Additional file 18: Text S1. The list of NCBI Genbank accession numbers for sweetpotato BESs. (TXT $298 \mathrm{~kb}$ ) 


\section{Abbreviations}

BAC: Bacterial artificial chromosome; BESs: BAC-end sequences; ESTs: Expressed sequence tags; GO: Gene ontology; HMW: High molecular weight; IbMIPS1: Ipomoea batatas myo-inositol-1-phosphate synthase gene; IbPPOS: Ipomoea batatas polyphenol oxidase; IPTG: Isopropyl $\beta$-D-1-thiogalactopyranoside; NCBI: National center for biotechnology information; NR: Non-redundant protein (NR) database; PCR: Polymerase chain reaction; PFGE: Pulsed field gel electrophoresis; SSR: Simple sequences repeat; X-Gal: 5-bromo-4-chloro-3-indolyl- $\beta$-d-galactopyranoside

\section{Acknowledgements}

We thank Dr. Daniel Q. Tong, University of Maryland, USA, for English improvement.

\section{Funding}

This work was supported by National Natural Science Foundation of China (31271777) and China Agriculture Research System (CARS-11).

\section{Availability of data and materials}

BAC-end sequences from this publication were available in NCBI GSS database (Additional file 18: Text S1). All of BESs analyzed were submitted to the GenBank GSS database with accession numbers KS309164-KS320705.

\section{Authors' contributions}

$\mathrm{HZ}, \mathrm{QL}$ and ZS designed the experiments; $\mathrm{HZ}$, ZS and BD constructed and characterized BAC library; ZS, JH and $\mathrm{HZ}$ analyzed BESS; ZS and QL detected SSRs; HZ, QL, ZS and SH analyzed data; HZ, QL and ZS wrote the manuscript. All authors read and approved the final manuscript.

\section{Competing interests}

The authors declare that they have no competing interests.

\section{Consent for publication}

Not applicable.

\section{Ethics approval and consent to participate}

Not applicable.

Received: 23 January 2016 Accepted: 15 November 2016 Published online: 21 November 2016

\section{References}

1. FAOSTA. [http://faostat3.fao.org/download/Q/QC/E], Accessed 30 May 2014.

2. Santa-Maria MC. Studies for the genetic engineering of sweetpotato (Ipomoea batatas L.) for starch bioconversion. Ann Arbor: North Carolina State University; 2009.

3. Low JW, Arimond M, Osman N, Cunguara B, Zano F, Tschirley D. A foodbased approach introducing orange-fleshed sweet potatoes increased vitamin A intake and serum retinol concentrations in young children in rural Mozambique. J Nutr. 2007;137(5):1320-7.

4. Kurata R, Adachi M, Yamakawa O, Yoshimoto M. Growth suppression of human cancer cells by polyphenolics from sweetpotato (Ipomoea batatas L.) leaves. J Agr Food Chem. 2007;55(1):185-90.

5. Loebenstein G, Thottappilly G. The Sweetpotato. 1st ed. Berlin: Springer Netherlands; 2009

6. Hirakawa H, Okada Y, Tabuchi H, Shirasawa K, Watanabe A, Tsuruoka $H$, et al. Survey of genome sequences in a wild sweet potato, Ipomoea trifida $(\mathrm{H}$. B. K.) G. Don. DNA Res. 2015;22(2):171-9.

7. Wang Z, Fang B, Chen J, Zhang X, Luo Z, Huang L, et al. De novo assembly and characterization of root transcriptome using Illumina paired-end sequencing and development of cSSR markers in sweetpotato (Ipomoea batatas). BMC Genomics. 2010;11(1):726.

8. Wang Z, Fang B, Chen X, Liao M, Chen J, Zhang X, et al. Temporal patterns of gene expression associated with tuberous root formation and development in sweetpotato (Ipomoea batatas). BMC Plant Biol. 2015;15(1):180.

9. Firon N, LaBonte D, Villordon A, Kfir Y, Solis J, Lapis E, et al. Transcriptional profiling of sweetpotato (Ipomoea batatas) roots indicates down-regulation of lignin biosynthesis and up-regulation of starch biosynthesis at an early stage of storage root formation. BMC Genomics. 2013;14(1):460.
10. Tao X, Gu Y, Jiang $Y$, Zhang $Y$, Wang $H$. Transcriptome analysis to identify putative floral-specific genes and flowering regulatory-related genes of sweet potato. Biosci Biotech Bioch. 2013;77(11):2169-74.

11. Xie F, Burklew CE, Yang Y, Liu M, Xiao P, Zhang B, et al. De novo sequencing and a comprehensive analysis of purple sweet potato (Ipomoea batatas L.) transcriptome. Planta. 2012;236(1):101-13.

12. Ma P, Bian X, Jia Z, Guo X, Xie Y. De novo sequencing and comprehensive analysis of the mutant transcriptome from purple sweet potato (Ipomoea batatas L.). Gene. 2016;575(2, Part 3):641-9.

13. Li R, Zhai H, Kang C, Liu D, He S, Liu Q. De Novo Transcriptome sequencing of the orange-fleshed sweet potato and analysis of differentially expressed genes related to carotenoid biosynthesis. I nt J Genomics. 2015;2015(2015):843802.

14. Yan L, Lai X, Li X, Wei C, Tan X, Zhang Y. Analyses of the complete genome and gene expression of chloroplast of sweet potato [lpomoea batata]. PLoS One. 2015;10(4), e0124083.

15. Chen MS, Presting G, Barbazuk WB, Goicoechea JL, Blackmon B, Fang FC, et al. An integrated physical and genetic map of the rice genome. Plant Cell. 2002:14(3):537-45

16. Mueller LA, Tanksley SD, Giovannoni JJ, van Eck J, Stack S, Choi D, et al. The Tomato Sequencing Project, the first cornerstone of the International Solanaceae Project (SOL). Comp Funct Genomics. 2005;6(3):153-8.

17. Luo M, Gu YQ, You FM, Deal KR, Ma Y, Hu Y, et al. A 4-gigabase physical map unlocks the structure and evolution of the complex genome of Aegilops tauschii, the wheat D-genome progenitor. P Natl Acad Sci USA. 2013;110(19):7940-5.

18. Edwards D, Batley J, Snowdon RJ. Accessing complex crop genomes with next-generation sequencing. Theor Appl Genet. 2013;126(1):1-11.

19. Wu J, Gu YQ, Hu Y, You FM, Dandekar AM, Leslie CA, et al. Characterizing the walnut genome through analyses of BAC end sequences. Plant Mol Biol. 2012;78(1-2):95-107

20. Rajesh PN, O'Bleness M, Roe BA, Muehlbauer FJ. Analysis of genome organization, composition and microsynteny using $500 \mathrm{~kb}$ BAC sequences in chickpea. Theor Appl Genet. 2008:117(3):449-58.

21. Myers EW, Sutton GG, Delcher AL, Dew IM, Fasulo DP, Flanigan MJ, et al. A whole-genome assembly of Drosophila. Science. 2000;287(5461):2196-204.

22. Zhao L, Zhang Y, Ji P, Zhang X, Zhao Z, Hou G, et al. A dense genetic linkage map for common carp and its integration with a BAC-based physical map. PLoS One. 2013;8(5), e639285.

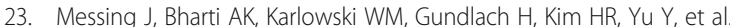
Sequence composition and genome organization of maize. P Natl Acad Sci USA. 2004;101(40):14349-54.

24. Paux E, Roger D, Badaeva E, Gay G, Bernard M, Sourdille P, et al. Characterizing the composition and evolution of homoeologous genomes in hexaploid wheat through BAC-end sequencing on chromosome 3B. The Plant J. 2006:48(3):463-74.

25. Han Y, Korban SS. An overview of the apple genome through BAC end sequence analysis. Plant Mol Biol. 2008;67(6):581-8.

26. Ferreira de Carvalho J, Chelaifa H, Boutte J, Poulain J, Couloux A, Wincker $P$, et al. Exploring the genome of the salt-marsh Spartina maritima (Poaceae, Chloridoideae) through BAC end sequence analysis. Plant Mol Biol. 2013; 83(6):591-606

27. Kim C, Lee T, Compton RO, Robertson JS, Pierce GJ, Paterson AH. A genome-wide BAC end-sequence survey of sugarcane elucidates genome composition, and identifies BACs covering much of the euchromatin. Plant Mol Biol. 2013;81(1-2):139-47.

28. Dereeper A, Guyot R, Tranchant-Dubreuil C, Anthony F, Argout X, de Bellis F, et al. BAC-end sequences analysis provides first insights into coffee (Coffed canephora P.) genome composition and evolution. Plant Mol Biol. 2013; 83(3):177-89.

29. Santos AA, Penha HA, Bellec A, Munhoz CDF, Pedrosa-Harand A, Berges $H$ et al. Begin at the beginning: A BAC-end view of the passion fruit (Passiflora) genome. BMC Genomics. 2014;15(1):816.

30. Zhai H, Liu Q. Expression analysis of sweet potato myo-inositol-I-phosphate synthase gene. Mol Plant Breeding. 2009;7(3):537-44

31. Temnykh S, DeClerck G, Lukashova A, Lipovich L, Cartinhour S, McCouch S. Computational and experimental analysis of microsatellites in rice (Oryza sativa L.): Frequency, length variation, transposon associations, and genetic marker potential. Genome Res. 2001;11(8):1441-52.

32. Rampant PF, Lesur I, Boussardon C, Bitton F, Martin-Magniette M, Bodenes $C$, et al. Analysis of BAC end sequences in oak, a keystone forest tree 
species, providing insight into the composition of its genome. BMC Genomics. 2011;12(1):292.

33. Fang $X, G u S, X u Z$, Chen F, Guo D, Zhang HB, et al. Construction of a binary BAC library for an apomictic monosomic addition line of Beta corolliflora in sugar beet and identification of the clones derived from the alien chromosome. Theor Appl Genet. 2004;108(7):1420-5.

34. Yüksel B, Paterson AH. Construction and characterization of a peanut HindllI BAC library. Theor Appl Genet. 2005;111(4):630-9.

35. Gao LL, Hane JK, Kamphuis LG, Foley R, Shi BJ, Atkins CA, et al. Development of genomic resources for the narrow-leafed lupin (Lupinus angustifolius): construction of a bacterial artificial chromosome (BAC) library and BAC-end sequencing. BMC Genomics. 2011;12(1):1.

36. Datema E, Mueller LA, Buels R, Giovannoni JJ, Visser RG, Stiekema WJ, et al. Comparative BAC end sequence analysis of tomato and potato reveals overrepresentation of specific gene families in potato. BMC Plant Biol. 2008;8(1):34.

37. Feldman M, Levy AA. Allopolyploidy - a shaping force in the evolution of wheat genomes. Cytogenet Genome Res. 2005;109(1-3):250-8.

38. Ma XF, Gustafson JP. Genome evolution of allopolyploids: a process of cytological and genetic diploidization. Cytogenet Genome Res. 2005; 109(1-3):236-49.

39. Xu X, Pan S, Cheng S, Zhang B, Mu D, Ni P, et al. Genome sequence and analysis of the tuber crop potato. Nature. 2011:475(7355):189-94.

40. Brenchley R, Spannagl M, Pfeifer M, Barker GLA, D'Amore R, Allen AM, et al. Analysis of the bread wheat genome using whole-genome shotgun sequencing. Nature. 2012;491(7426):705-10.

41. Kumar A, Bennetzen JL. Retrotransposons: Central players in the structure, evolution and function of plant genomes. Trends Plant Sci. 2000;5(12):509-10.

42. Terol J, Naranjo MA, Ollitrault P, Talon M. Development of genomic resources for Citrus clementina: Characterization of three deep-coverage BAC libraries and analysis of 46,000 BAC end sequences. BMC Genomics. 2008;9(1):423.

43. Zhao M, Ma J. Co-evolution of plant LTR-retrotransposons and their host genomes. Protein Cell. 2013;4(7):493-501.

44. Lai CWJ, Yu Q, Hou S, Skelton RL, Jones MR, Lewis KLT, et al. Analysis of papaya BAC end sequences reveals first insights into the organization of a fruit tree genome. Mol Genet Genomics. 2006;276(1):1-12.

45. Schlueter JA, Goicoechea JL, Collura K, Gill N, Lin JY, Yu YS, et al. BAC-end sequence analysis and a draft physical map of the common bean (Phaseolus vulgaris L.) genome. Trop Plant Biol. 2008;1 (1):40-8.

46. Gonzalez VM, Rodriguez-Moreno L, Centeno E, Benjak A, Garcia-Mas J, Puigdomenech P, et al. Genome-wide BAC-end sequencing of Cucumis melo using two BAC libraries. BMC Genomics. 2010;11(1):618.

47. Powell W, Morgante M, Andre C, Hanafey M, Vogel J, Tingey S, et al. The comparison of RFLP, RAPD, AFLP and SSR (microsatellite) markers for germplasm analysis. Mol Breeding. 1996;2(3):225-38.

48. de Faria Müller BSO, Sakamoto T, de Menezes IPP, Prado GS, Martins WS, Brondani $C$, et al. Analysis of BAC-end sequences in common bean (Phaseolus vulgaris L.) towards the development and characterization of long motifs SSRs. Plant Mol Biol. 2014;86(4-5):455-70.

49. Wang H, Penmetsa RV, Yuan M, Gong L, Zhao Y, Guo B, et al. Development and characterization of BAC-end sequence derived SSRs, and their incorporation into a new higher density genetic map for cultivated peanut (Arachis hypogaea L.). BMC Plant Biol. 2012;12:10.

50. Wang Z, Li J, Luo Z, Huang L, Chen X, Fang B, et al. Characterization and development of EST-derived SSR markers in cultivated sweetpotato (Ipomoea batatas). BMC Plant Biol. 2011;11(1):1.

51. Orjeda G, Freyre R, Iwanaga M. Use of Ipomoea trifida germplasm for sweet potato improvement. 3. Development of $4 x$ interspecific hybrids between Ipomoea batatas (L.) Lam. $(2 n=6 x=90)$ and I. trifida (H.B.K) G. Don. $(2 n=2 x=30)$ as storage-root initiators for wild species. Theor Appl Genet. 1991;83(2):159-63.

52. Srisuwan S, Sihachakr D, Siljak-Yakovlev S. The origin and evolution of sweet potato (Ipomoea batatas Lam.) and its wild relatives through the cytogenetic approaches. Plant Sci. 2006;171(3):424-33.

53. Huang JC, Sun M. Genetic diversity and relationships of sweetpotato and its wild relatives in Ipomoea series Batatas (Convolvulaceae) as revealed by inter-simple sequence repeat (ISSR) and restriction analysis of chloroplast DNA. Theor Appl Genet. 2000;100(7):1050-60.

54. Roullier C, Duputie A, Wennekes P, Benoit L, Fernandez Bringas VM, Rossel $\mathrm{G}$, et al. Disentangling the origins of cultivated sweet potato (Ipomoea batatas (L.) Lam.). PLoS One. 2013;8(5):e627075.
55. Wikstrom N, Savolainen V, Chase MW. Evolution of the angiosperms: calibrating the family tree. P Roy Soc B-Biol Sci. 2001;268(1482):2211-20.

56. Jaillon O, Aury J, Noel B, Policriti A, Clepet C, Casagrande A, et al. The grapevine genome sequence suggests ancestral hexaploidization in major angiosperm phyla. Nature. 2007;449(7161):463-5.

57. Zhao N, Yu X, Jie Q, Li H, Li H, Hu J, et al. A genetic linkage map based on AFLP and SSR markers and mapping of QTL for dry-matter content in sweetpotato. Mol Breeding. 2013;32(4):807-20.

58. Zhang $H$, Zhao X, Ding X, Paterson AH, Wing RA. Preparation of megabasesize DNA from plant nuclei. The Plant J. 1995;7(1):175-84.

59. Sambrook J, Russell DW. Molecular cloning: A laboratory manual. 3rd ed. Longlsland: Cold Spring Harbor Laboratory Press; 2009

60. Clarke L, Carbon J. A colony bank containing synthetic Col El hybrid plasmids representative of the entire E. coli genome. Cell. 1976;9(1):91-9.

61. Koressaar T, Remm M. Enhancements and modifications of primer design program Primer3. Bioinformatics. 2007;23(10):1289-91.

62. Untergasser A, Cutcutache I, Koressaar T, Ye J, Faircloth BC, Remm M, et al. Primer3-new capabilities and interfaces. Nucleic Acids Res. 2012; 40(15), e11515.

63. Farrar K, Donnison IS. Construction and screening of BAC libraries made from Brachypodium genomic DNA. Nat Protoc. 2007;2(7):1661-74.

64. Ewing B, Hillier L, Wendl MC, Green P. Base-calling of automated sequencer traces using Phred. I. Accuracy assessment. Genome Res. 1998;8(3):175-85.

65. Gordon D, Abajian C, Green P. Consed: A graphical tool for sequence finishing. Genome Res. 1998;8(3):195-202.

66. Smit AFA, Hubley R, Green P. RepeatMasker Open-4.0. 1996-2015. < http:// www.repeatmasker.org >. Accessed 25 July 2013.

67. Smit AFA, Hubley R. RepeatModeler Open-1.0. 2008-2015. < http://www. repeatmasker.org >. Accessed 30 July 2013.

68. Abrusan G, Grundmann N, DeMester L, Makalowski W. TEclass-a tool for automated classification of unknown eukaryotic transposable elements. Bioinformatics. 2009;25(10):1329-30.

69. Solanum lycopersicum protein database. ftp://ftp.ncbi.nlm.nih.gov/genomes/ Solanum_lycopersicum/protein/protein.fa.gz. Accessed 20 Nov 2014.

70. Vitis vinifera protein database. ftp://ftp.ncbi.nlm.nih.gov/genomes/Vitis_ vinifera/protein/protein.fa.gz. Accessed 11 Dec 2014.

71. Conesa A, Gotz S, Garcia-Gomez JM, Terol J, Talon M, Robles M. Blast2GO: a universal tool for annotation, visualization and analysis in functional genomics research. Bioinformatics. 2005;21(18):3674-6.

72. Thiel T, Michalek W, Varshney RK, Exploiting GA, EST. databases for the development and characterization of gene-derived SSR-markers in barley (Hordeum vulgare L.). Theor Appl Genet. 2003;106(3):411-22.

73. National Center for Biotechnology Information genome database. ftp://ftp. ncbi.nlm.nih.gov/genomes/. Accessed 2 Dec 2014.

74. Krzywinski M, Schein J, Birol I, Connors J, Gascoyne R, Horsman D, et al. Circos: An information aesthetic for comparative genomics. Genome Res. 2009;19(9):1639-45.

\section{Submit your next manuscript to BioMed Central and we will help you at every step:}

- We accept pre-submission inquiries

- Our selector tool helps you to find the most relevant journal

- We provide round the clock customer support

- Convenient online submission

- Thorough peer review

- Inclusion in PubMed and all major indexing services

- Maximum visibility for your research

Submit your manuscript at www.biomedcentral.com/submit
Biomed Central 